\title{
Reliability Analysis of Adhesively Bonded CFRP-to-steel Double Lap Shear Joint with Thin Outer Adherends
}

\author{
Meng Liu and Mina Dawood* \\ Civil and Environmental Engineering Department, University of Houston, 4726 Calhoun Road, Room N107 \\ Engineering Building 1, Houston, TX 77204-4003, USA. \\ * Corresponding author, \\ E-mail address: mmdawood@central.uh.edu (M. Dawood).
}

\begin{abstract}
This paper presents the details of a reliability-based analysis of bonded double-lap shear (DLS) joints between steel and carbon fiber reinforced polymer (CFRP) composites. A comprehensive database of experimental results of CFRP-to-steel DLS joints is compiled and a probabilistic analysis of the data is conducted. The compiled experimental results are compared with the bond strengths predicted by the Hart-Smith model for thin adherends and the model uncertainty is characterized, for five popular structural epoxy adhesives and two types of surface preparation techniques. Considering the mechanical and geometrical uncertainties of constituent materials, two reliability-based approaches, First-Order Reliability Method (FORM) and Monte-Carlo Simulation (MCS), are used to calculate the resistance factor at a target reliability index of 3.5. It is found that these two approaches agree well and the resistance factor varies with adhesives, surface preparation techniques, and CFRP types. The importance vector of random variables reveals that the adhesive shear ductility is the most influential material property in determining the reliability index of the bonded joints.
\end{abstract}

Abbreviations: CFRP: carbon fiber reinforced polymer; DLS: double lap-shear; FORM: First-Order Reliability Method; FEA: Finite Element Analysis; MCS: Monte-Carlo Simulation; COV: coefficient of variation; LSE: least-square estimation; A: Araldite 420; S: Sikadur 30; TT: Tyfo TC; TS: Tyfo S; MB: 
Mbrace Saturant; AG: angle-grinding; SB: sand-blasting; WL: Wet lay-up; PL: Pultruded laminate; SA: steel-adhesive interface debonding failure; $\mathrm{C}$ : cohesive failure.

Keywords: Adhesive; Surface Preparation; Double Lap-Shear; Model Uncertainty; Reliability; Bond Strength, Ductility.

\section{Introduction}

The use of carbon fiber-reinforced polymers (CFRP) to repair, rehabilitate, and strengthen steel beams has been widely researched in recent years because of its light-weight construction and corrosion resistance [1-9]. Debonding is a key failure mode associated with the CFRP strengthened steel beams, and the debonding failure load is affected by the mechanical properties of the adhesive and bi-material interfaces [2,9-12]. Recent developments in CFRP strengthening technique showed that CFRP materials with smalldiameter strands can potentially eliminate debonding failure [13]

It has been demonstrated that surface preparation is important to obtain good bonding between the adherends [14-16]. A clean, rough and chemically reactive surface is preferable for adhesive bonding, especially for CFRP-to-steel bonding, where the steel-adhesive interface is often the weakest link in the joint. A thorough study of the surface preparation for epoxy to steel bonding was carried out by Fernando et al. [17], and it showed that the grit-blasting technique is the most effective way to achieve good bond between epoxy and steel.

Double-lap shear (DLS) joints are commonly used to study the bond behavior between steel and CFRP since the shear and peeling stress distributions within the adhesive layer for long DLS joints are similar to those in CFRP strengthened beams under flexural loading [4,18-22]. Experimental studies showed that debonding loads exhibit higher variability compared with those of other failure modes such as steel yielding and CFRP rupture [23-24]. However, the guidelines for structural design using composite 
material and adhesive for steel strengthening do not have quantitative assessment of the variability of debonding strength, and probability-based resistance factors for such bonded joint are not available [2526].

Models for lap-shear joint based on first-order shear lag analysis [27-28] provide relatively straight forward closed-form solutions that can be implemented by hand in design code. Although they do not capture the variability of stresses through the thickness of the adhesive layer and violate the zero shear condition at the end of the joint. Higher order model [29] addresses these shortcomings but requires iterative solutions and is not well suited for design. Fracture mechanics based solutions [20, 30] can represent the underlying mechanics of the problem more accurately, but they usually require numerical analysis to calculate the stress intensity factors or energy release rate making them difficult to recommend for design applications. Finite element analysis (FEA) models [20, 23, 30] and bond-slip based model [31-32] are often limited by the joint configuration and are difficult to be applied to more general cases. Moreover, the computational cost of Monte-Carlo simulation (MCS) by adopting models relied on numerical analysis can be formidably high.

The debonding strength of DLS joint is affected by both shear and peeling stresses at the joint ends. DLS joint with thick outer adherends tends to fail prematurely due to the high magnitude of peeling stress, also called adherend-induced failure [27]. The peeling stress can be neglected if the outer adherends are thin enough, as formulated in Hart-Smith model [27]. This provides an opportunity to study the reliability of DLS joint, under limit state governed by shear only and the complexity of considering peeling stress can be eliminated.

To this end, the uncertainty associated with CFRP-to-steel bond needs to be quantified. This paper presents the findings of a reliability-based study of CFRP-to-steel adhesively bonded DLS joints that 
failed by debonding limit state. Primary sources of uncertainty, including the type of adhesive used, the surface preparation, the representation of the constitutive relationship of the adhesive in shear, the type of CFRP used and the modeling uncertainty are quantified and discussed. A database of 270 experimental results on CFRP-to-steel bonded DLS joints was compiled to quantify the model uncertainty of the analytical model [27]. The First-Order Reliability Method (FORM) was used and validated using MCS, to study the influence of the uncertainty of different parameters on the predicted bond strength and to calculate the resistance factors for bonded joints. Due to the similarity between debonding of DLS joints and beams, these findings can inform future reliability-based studies to calibrate resistance factors for design specifications.

\section{CFRP-to-steel DLS Joint Details}

The CFRP-to-steel DLS joint is made by bonding CFRP laminates (or carbon fiber fabrics) on both sides of two butted steel plates, as shown in Figure 1. Prior to bonding, the steel surfaces are often treated by sand-blasting or ground by an angle grinder, and cleaned with organic solvents such as Acetone. Different fabrication method is used for pultruded or wet lay-up CFRP laminate: 1) for pultruded laminate, paste adhesive is applied uniformly before applying the CFRP plate, and clamps or weights are used to squeeze out the excessive adhesive to ensure a thin and uniform adhesive layer (adhesive thickness can be controlled by using glass beads as spacer) 2) for wet lay-up laminate, carbon fiber fabrics are bonded to steel with a paste adhesive or saturate resin, and a roller is used to squeeze the excessive adhesive and air bubbles. Detailed fabrication methods can be found for pultruded [33] and wet lay-up laminate [31].

For all of the DLS specimens surveyed in this study, the outer CFRP adherends were thin compared with the inner steel adherends, if the thickness is less than [27] 


$$
t_{\text {CFRP_max }}=\frac{E_{\text {CFRP }} t_{\mathrm{a}}}{3\left(1-v^{2}\right)} \frac{1}{E_{\mathrm{a}}{ }^{\prime}}\left(\frac{\sigma_{\mathrm{p}}}{\tau_{\mathrm{p}}}\right)^{4}
$$

where, $E_{\mathrm{CFRP}}$ is the modulus of the CFRP adherend, $v$ is the Poisson's ratio of the adhesive, $t_{\mathrm{a}}$ is the adhesive layer thickness, $E_{\mathrm{a}}{ }^{\prime}$ is the elastic modulus of adhesive layer loaded in normal direction, $\sigma_{\mathrm{p}}$ and $\tau_{\mathrm{p}}$ are the peel and shear strength of the adhesive, respectively. The shear stress in the adhesive layer is dominant if the thin adherend criterion is met. By considering these specific joint configurations, the uncertainty associated with the peeling component of the stress, can be excluded in the reliability-based analysis which reflects the range of configurations that were identified in the published literature. Steel plates were used as the inner adherends and the axial rigidity of the inner adherends was higher than that of the outer adherends, so an imbalanced joint configuration was achieved. The joints were all loaded in axial tension, as shown in Figure 1, inducing a predominantly shear stress in the bonded joint (peeling stresses are negligible according to the Hart-Smith formulation).

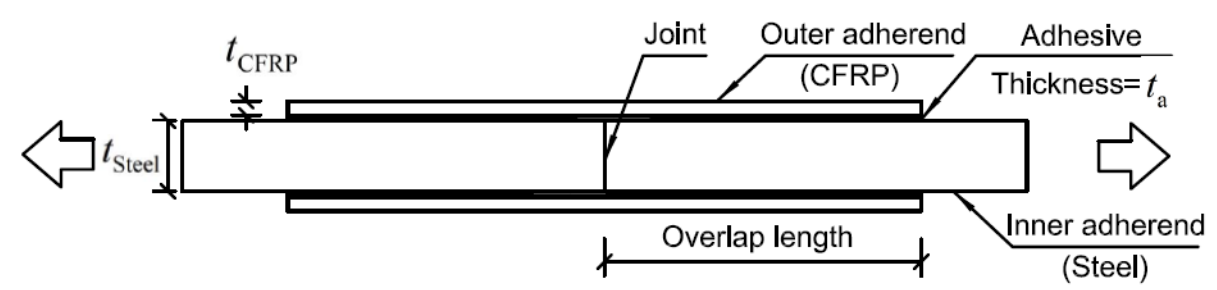

Figure 1 Schematic of CFRP-to-steel DLS joint (not to scale)

\section{Limit State Function}

Several failure modes were identified for CFRP-to-steel bonded joints [34]. Of which debonding failure, i.e. cohesive or adhesive failure modes, are of the primary interest. The cohesive failure, where the debonding occurs within the adhesive layer, is often governed by the strength of the adhesive material. For adhesive failure mode, the debonding occurs at the adhesive/steel or adhesive/CFRP interface and is 
governed by the strength of the interfaces. The resistance and load models for the debonding limit state are expressed in the following sections.

\subsection{Resistance Model}

The predicted bond strength of a DLS joint with thin outer adherends, $P_{\mathrm{p}}$, was determined by Hart-Smith [27] to be

$$
\begin{gathered}
P_{\mathrm{p}}=b \sqrt{2 t_{\mathrm{a}} \tau_{\mathrm{p}}\left(\frac{1}{2} \gamma_{\mathrm{e}}+\gamma_{\mathrm{p}}\right) 4 E_{\mathrm{CFRP}} t_{\mathrm{CFRP}}\left(1+\frac{2 E_{\mathrm{CFRP}} t_{\mathrm{CFRP}}}{E_{\text {steel }} t_{\text {steel }}}\right)} \\
\text { for } E_{\text {steel }} t_{\text {steel }} \geq 2 E_{\mathrm{CFRP}} t_{\mathrm{CFRP}}
\end{gathered}
$$

where, $b$ is the width of the joint, $t_{\mathrm{a}}$ is the adhesive layer thickness, $\tau_{\mathrm{p}}$ is the shear yield strength of the adhesive if an elastic-perfectly plastic material model is used, $\gamma_{\mathrm{e}}$ and $\gamma_{\mathrm{p}}$ are the maximum elastic and plastic shear strains, respectively, $E_{\mathrm{CFRP}}$ is the CFRP modulus in the longitudinal direction and $E_{\text {steel }}$ is the Young's modulus of steel, $t_{\mathrm{CFRP}}$ is the CFRP thickness and $t_{\text {steel }}$ is the steel plate thickness, as shown in

Figure 1. The shear toughness of the adhesive, $U_{\text {shear }}$ is defined as

$$
U_{\text {shear }}=\tau_{\mathrm{p}}\left(\frac{1}{2} \gamma_{\mathrm{e}}+\gamma_{\mathrm{p}}\right)
$$

It can also be represented graphically by the area underneath the shear stress-strain curve as shown in Figure 2 


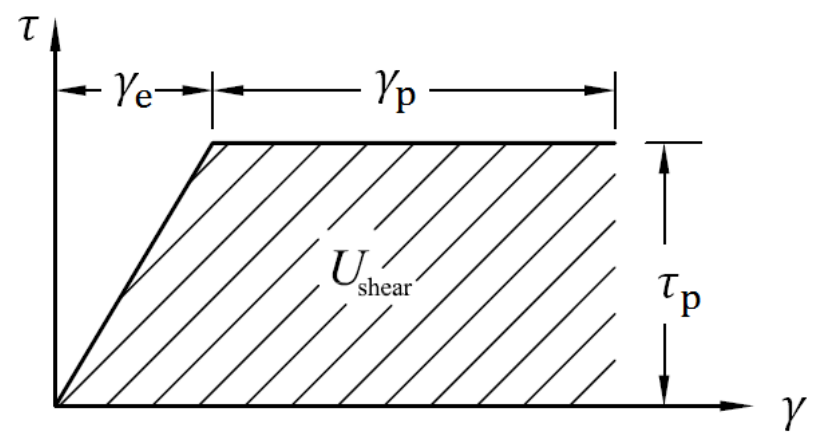

Figure 2 Schematic of the elastic-perfect plastic model characterization

So the joint capacity can be rewritten as:

$$
P_{\mathrm{p}}=b \sqrt{2 t_{\mathrm{a}} U_{\text {shear }} 4 E_{\mathrm{CFRP}} t_{\mathrm{CFRP}}\left(1+\frac{2 E_{\mathrm{CFRP}} t_{\mathrm{CFRP}}}{E_{\text {Steel }} t_{\text {Steel }}}\right)}
$$

The minimum overlap length (or critical overlap length) to achieve this bond strength is

$$
l_{o}=\frac{P_{\mathrm{p}}}{2 b \tau_{\mathrm{p}}}+\frac{2}{\lambda}
$$

where

$$
\lambda=\sqrt{\frac{G_{\mathrm{a}}}{t_{\mathrm{a}}}\left(\frac{1}{E_{\mathrm{CFRP}} t_{\mathrm{CFRP}}}+\frac{2}{E_{\text {steel }} t_{\text {steel }}}\right)}
$$

$G_{\mathrm{a}}$ is the shear modulus of the adhesive. For DLS joints with overlap lengths, $l$, smaller than $l_{o}$, the bond strength is estimated as:

$$
P_{\mathrm{ult}, l}=P_{\mathrm{ult}} \frac{l}{l_{o}}
$$


This simplification is convenient for design but it introduces additional modeling uncertainty when predicting the bond strength for DLS joints with shorter overlap lengths, since the bond strength does not follow a linear relationship with respect to the overlap length for shorter overlap lengths [27]. Considering the model uncertainty

$$
\xi_{R}=\frac{P_{\mathrm{m}}}{P_{\mathrm{p}}}
$$

where $P_{\mathrm{m}}$ is the actual bond strength obtained from experiments, the resistance model can then be written as

$$
R=\xi_{R} b \sqrt{2 t_{\mathrm{a}} \tau_{\mathrm{p}}\left(\frac{1}{2} \gamma_{\mathrm{e}}+\gamma_{\mathrm{p}}\right) 4 E_{\mathrm{CFRP}} t_{\mathrm{CFRP}}\left(1+\frac{2 E_{\mathrm{CFRP}} t_{\mathrm{CFRP}}}{E_{\text {steel }} t_{\text {steel }}}\right)}
$$

\subsection{Demand model}

If only live load and dead load are considered, the nominal demand and resistance are related at the design point [35]

$$
\gamma_{\mathrm{DL}} Q_{\mathrm{DL}}+\gamma_{\mathrm{LL}} Q_{\mathrm{LL}}=\phi R_{\mathrm{n}}
$$

where $Q_{\mathrm{DL}}$ is the nominal dead load and $Q_{\mathrm{LL}}$ is the nominal live load, and $\gamma_{\mathrm{DL}}, \gamma_{\mathrm{LL}}$ are the load factors for dead load and live load, respectively. The nominal resistance, $R_{\mathrm{n}}$, is calculated by employing the nominal values of design variables, $\phi$ is the resistance factor. Since CFRP-to-steel strengthening may be applied to various structure types, live-to-dead load ratios, $n_{\mathrm{L}}=Q_{\mathrm{LL}} / Q_{\mathrm{DL}}$, ranging from 0 to 4 were considered. Therefore, the nominal dead and live load at the design point can be expressed in terms of the resistance [36]. Similarly, the variability of the dead and live loads can be characterized by demand model uncertainty, $\zeta_{Q}$, which is defined as: 


$$
\zeta_{Q}=\frac{Q_{\mathrm{m}}}{Q_{\mathrm{p}}}
$$

where $Q_{\mathrm{m}}$ is the actual load by measurement, and $Q_{\mathrm{p}}$ is the predicted load. Consequently, the demand $Q$ can be written as:

$$
Q=\zeta_{\mathrm{DL}} Q_{\mathrm{DL}}+\zeta_{\mathrm{LL}} Q_{\mathrm{LL}}
$$

$\zeta_{\mathrm{DL}}$ and $\zeta_{\mathrm{LL}}$ are the model uncertainty for dead load and live load, respectively. When treated as random variables, the corresponding bias $\lambda_{Q}$ and coefficient of variation (COV) for the load model uncertainty can be defined as:

$$
\begin{gathered}
\lambda_{Q}=\mu\left(\zeta_{Q}\right)=\mu\left(\frac{Q_{\mathrm{m}}}{Q_{\mathrm{p}}}\right) \\
\operatorname{cov}\left(\zeta_{Q}\right)=\frac{\sigma\left(\zeta_{Q}\right)}{\mu\left(\zeta_{Q}\right)}=\frac{\sigma\left(\frac{Q_{\mathrm{m}}}{Q_{\mathrm{p}}}\right)}{\mu\left(\frac{Q_{\mathrm{m}}}{Q_{\mathrm{p}}}\right)}
\end{gathered}
$$

The load factor can then be estimated as [37]:

$$
\gamma_{Q}=\lambda_{Q}\left[1+n_{\sigma} \operatorname{cov}\left(\zeta_{Q}\right)\right]
$$

Where $n_{\sigma}$ is a constant representing the number of standard deviations from the mean needed to obtain the desired probability of exceedance, based on past practice, $n_{\sigma}=2$ is recommended [37].

The limit state function for reliability analysis is defined as:

$$
g=R-Q
$$


where $R$ and $Q$ are the random variables representing the resistance (capacity) and demand (load), respectively. Substituting Eqns. (9), (10) and (12) into Eqn. (16) and using $\gamma_{\mathrm{e}}=\tau_{\mathrm{p}} / G_{\mathrm{a}}$, the limit state function becomes

$$
g(\boldsymbol{X})=\xi_{R} b \sqrt{\left(\frac{\tau_{\mathrm{p}}^{2} t_{\mathrm{a}}}{G_{\mathrm{a}}}+2 \tau_{\mathrm{p}} t_{\mathrm{a}} \gamma_{\mathrm{p}}\right) 4 E_{\mathrm{CFRP}} t_{\mathrm{CFRP}}\left(1+\frac{2 E_{\mathrm{CFRP}} t_{\mathrm{CFRP}}}{E_{\text {steel }} t_{\text {steel }}}\right)}-\frac{\phi R_{\mathrm{n}}}{\gamma_{\mathrm{DL}}+\gamma_{\mathrm{LL}} n_{\mathrm{L}}}\left(\zeta_{\mathrm{DL}}+\zeta_{\mathrm{LL}} n_{\mathrm{L}}\right)
$$

For the mechanical properties of the constituent materials, the modulus of steel and pultruded CFRP were treated deterministically since the variability is negligible [38-40]. Similarly, the variability of the geometry (width and thickness) of steel and pultruded CFRP is also very small [39] compared with the thickness of the adhesive layer and the thickness of wet lay-up CFRP. Thus the geometric variables of the steel plate and pultruded CFRP were treated deterministically [40]. Consequently, the random variable vector $\boldsymbol{X}$ is written as: $\boldsymbol{X}=\left\{\tau_{\mathrm{p}}, G_{\mathrm{a}}, \gamma_{\mathrm{p}}, t_{\mathrm{a}}, E_{\mathrm{CFRP}}, t_{\mathrm{CFRP}}, \xi_{R}, \zeta_{\mathrm{DL}}, \zeta_{\mathrm{LL}}\right\}^{T}$

\section{Statistical Characteristics of Design Variables}

\subsection{Material Property Variables}

Among the materials being considered in these bonded joints, the structural adhesive has the highest variability compared with other constituent materials. The mixing and applying process of the adhesives can introduce defects to the bond, and the manufacturing process is considered as an important source of uncertainty for bond strength.

\subsubsection{Adhesive Toughness}

As indicated by the Hart-Smith model, all of the variables related to the adhesive material properties can be incorporated into one term, the adhesive shear toughness, $U_{\text {shear }}$. However, the shear stress-strain response and shear toughness are not typically available in published literature. Occasionally shear 
strength data are available through either bulk shear tests of the adhesives, or standard lap shear test results, however, these tests cannot quantify shear ductility or toughness. In-lieu, researchers often present the tensile response obtained from ASTM standard tension tests [41] presuming that the shear response is similar to the tensile response. However, this assumption might not hold for glassy structural adhesives.

Three different approaches were evaluated to incorporate the adhesive material properties into the resistance model. First, the equivalent shear properties were determined from the tensile properties. This is the most widely used approach to incorporate adhesive properties into the prediction of the debonding and assumes that adhesives with elastic tensile response will also exhibit elastic shear response. In the second approach, for one of the structural adhesives considered in this study, Araldite 420, the shear stress-strain response was available from the results of a novel type of adhesive shear test [42]. The experimentally obtained shear stress-strain response was implemented directly in the bond resistance model. This approach can be used when adhesive shear stress-strain data are available. In the third approach the shear-properties of the adhesive were estimated to minimize the squared error between the measured and predicted debonding loads as a means of estimating the adhesive shear property when these data are not explicitly available. Each approach is summarized and compared below. For illustrative purposes the shear stress-strain curves of the Araldite 420 adhesive obtained using the three methods are illustrated in Figure 3. The figure also presents the experimentally obtained tensile and shear stress-strain curves. Table 1 gives the relevant material parameters for implementation in the Hart-Smith model for each of the five adhesives considered in this study based on the three different methods described below. 


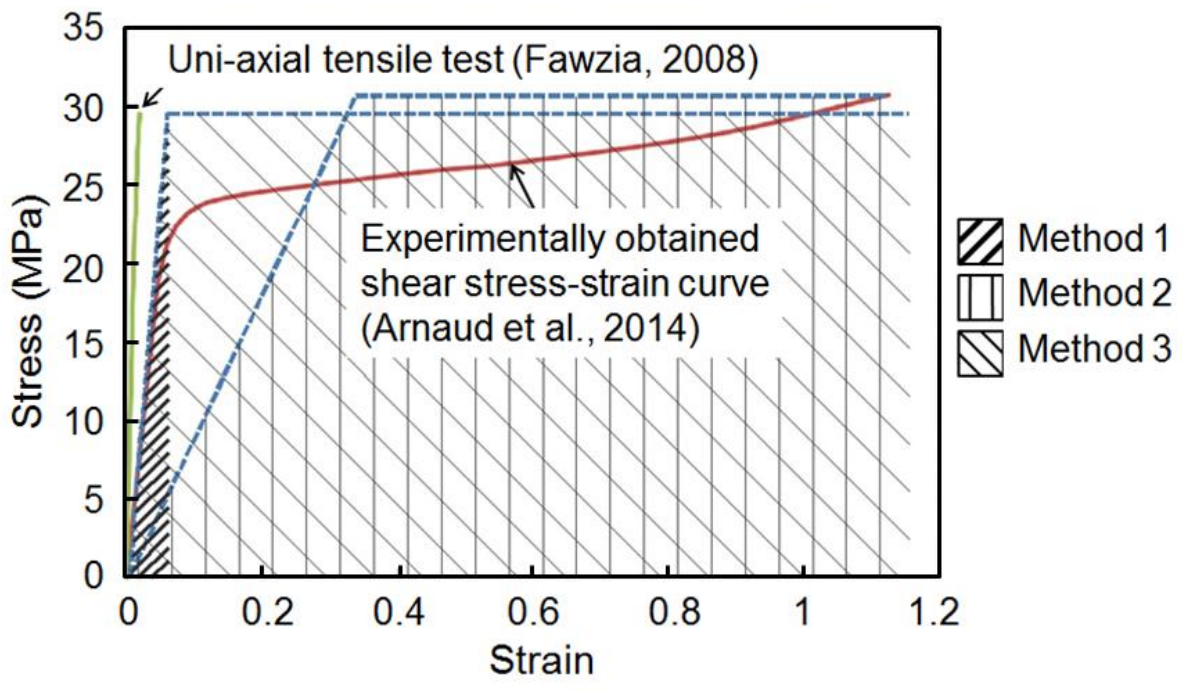

Figure 3 Comparison of the equivalent shear stress-strain curves obtained by different methods

Table 1 Mechanical properties of adhesives

\begin{tabular}{c|cccc|cccc|cccc}
\hline Adhesive & \multicolumn{5}{|c|}{ Method 1 } & \multicolumn{5}{|c|}{ Method 2 } & \multicolumn{4}{|c}{ Method 3 } \\
& $G_{\mathrm{a}}$ & $\tau_{\mathrm{p}}$ & $\gamma_{\mathrm{p}}$ & $U_{\text {shear }}$ & $G_{\mathrm{a}}$ & $\tau_{\mathrm{p}}$ & $\gamma_{\mathrm{p}}$ & $U_{\text {shear }}$ & $G_{\mathrm{a}}$ & $\tau_{\mathrm{p}}$ & $\gamma_{\mathrm{p}}$ & $U_{\text {shear }}$ \\
\hline${\text { Araldite } 420^{\mathrm{a}}}$ & 665 & 29.5 & 0 & 0.654 & 91 & $31.3^{\mathrm{c}}$ & 0.792 & $30.2^{\mathrm{c}}$ & 665 & 29.5 & 1.12 & 33.8 \\
Sikadur 30 $^{\mathrm{a}}$ & 3835 & 24.5 & 0 & 0.078 & $1680^{\mathrm{d}}$ & $24.5^{\mathrm{d}}$ & $0.103^{\mathrm{d}}$ & 2.70 & 3835 & 24.5 & 0.096 & 2.42 \\
Tyfo TC $^{\mathrm{b}}$ & 106 & 8.60 & 0.254 & 2.53 & N.A. & N.A. & N.A. & N.A. & 106 & 8.60 & 0.436 & 4.10 \\
Tyfo $^{\mathrm{b}}$ & 742 & 46.0 & 0 & 1.43 & N.A. & N.A. & N.A. & N.A. & 742 & 46.0 & 0.007 & 1.74 \\
MBrace $^{\mathrm{a}}$ & 770 & 25.0 & 0 & 0.406 & N.A. & N.A. & N.A. & N.A. & 770 & 25.0 & 0.004 & 4.15 \\
\hline
\end{tabular}

Notes: a.[43]; b. [14]; c. [42]; d. [23]. The unit of stress and toughness is in MPa.

Method 1: Shear properties based on tensile properties 
This method reflects how researchers commonly obtain the shear stress-strain response of an adhesive based on widely available tensile test data. Four of the adhesives considered in this study (Araldite 420, Sikadur 30, Tyfo S, and MBrace Saturant) exhibited brittle tensile stress-strain curves. For these brittle adhesives a maximum principal stress failure criterion was applied such that the shear strength, $\tau_{\mathrm{p}}$, was taken equal to the measured tensile strength, $f_{\mathrm{t}, \mathrm{a}}$. For these adhesives the shear ductility, $n_{\text {shear }}=\gamma_{\mathrm{p}} / \gamma_{\mathrm{e}}$ was taken equal to the tensile ductility, $n_{\text {tension }}=\varepsilon_{\mathrm{p}} / \varepsilon_{\mathrm{e}}$. Since all four adhesives have brittle tensile stress-strain curves, the plastic tensile strain, $\varepsilon_{\mathrm{p}}$, is considered to be negligible, i.e. $\varepsilon_{\mathrm{p}}=0$, which yields $\gamma_{\mathrm{p}}=0$. For the ductile adhesive, Tyfo TC, the von-Mises yield criterion was adopted, and the shear strength was expressed as:

$$
\tau_{\mathrm{p}}=\frac{f_{\mathrm{t}, \mathrm{a}}}{\sqrt{3}}
$$

Similarly, the shear ductility was taken equal to the tensile ductility. The shear modulus, $G_{\mathrm{a}}$, was calculated from the elastic modulus, $E_{\mathrm{a}}$, and Poisson's ratio, $v$, based on classical mechanics for a homogenous isotropic material,

$$
G_{\mathrm{a}}=\frac{E_{\mathrm{a}}}{2(1+v)}
$$

\section{Method 2: Explicitly defined adhesive shear properties}

For two of the adhesives considered in this study (Araldite 420 and Sikadur 30) the shear stress-strain relationships have been explicitly defined in the published literature. The shear stress-strain response of the Araldite 420 adhesive was determined experimentally through a novel torsion test of a butt joint between two moderately thick-walled steel cylinders subjected to torsion load [42]. The measured shearstress strain curve is given in Figure 3. It is observed that the ductility of the adhesive under shear is 
substantially higher than that from uni-axial tension tests (also shown in Figure 3). This has been documented in the past by others [44]. For the Sikadur 30 adhesive the shear stress-strain relationship was obtained through reverse characterization based on DLS test results using a non-linear FEA model [23]. Since the Hart-Smith model assumes an elastic-perfectly plastic adhesive response in shear, an equivalent elastic-perfectly plastic shear-stress strain curve was developed for each of these adhesives. For the equivalent elastic-perfectly plastic models, the shear toughness (area under the curve) was set to be equal to that of the experimentally (or numerically) determined shear stress-strain curve. The resulting stressstrain curve for the Araldite 420 adhesive is shown in Figure 3 and the parameters for the elastic-perfectly plastic curves for the two adhesives are given in Table 1.

\section{Method 3: Shear properties determined through optimization}

For adhesives for which the shear stress-strain response, shear ductility, and shear toughness were not explicitly presented in the literature, an optimization approach was adopted to estimate these parameters while minimizing the modeling error. The strengths of the adhesives were estimated for brittle and ductile adhesives based on the maximum principal stress or von Mises failure criteria as mentioned in "Method 1" while the shear moduli $G_{\mathrm{a}}$ were calculated from $E_{\mathrm{a}}$, and Poisson's ratio, $v$. The shear ductility for each adhesive was obtained by minimizing the sum of the least-square errors between the measured and predicted tensile failure loads of 270 DLS specimens that were compiled in the database described below. Using this approach, the DLS specimens in the database were categorized based on the adhesive type and surface preparation technique used in their fabrication. For each group of samples, the plastic shear strain, $\gamma_{\mathrm{p}}$, was estimated and the tensile failure loads of the DLS joints were calculated using the Hart-Smith

model. The value of $\gamma_{\mathrm{p}}$ for each configuration was iterated to minimize the Least Square Error, LSE:

$$
\mathrm{LSE}=\sum_{i=1}^{n}\left(P_{\mathrm{p}, i}-P_{\mathrm{m}, i}\right)^{2}
$$


where $P_{\mathrm{p}, i}$ and $P_{\mathrm{m}, i}$ are the predicted and measured bond strength of the $i$-th specimen.

Figure 3 shows the shear stress-strain response for the Araldite 420 adhesive as obtained from these different methods. The figure highlights the significant difference between the responses obtained experimentally from the tensile and shear tests. Further, while the optimized sheared stress-strain curve does not match the measured or equivalent bi-linear shear stress-strain responses, the corresponding shear toughness is within $11 \%$ of the experimentally obtained value. Table 1 gives the values of the adhesive properties obtained using the three methods for the five adhesives.

Bresson et al. [45] studied the statistical properties of an epoxy-based structural paste adhesive, the mechanical tests showed that the tensile strength and Young's modulus were similar to three of the adhesives studied here (Araldite 420, Tyfo S, and MBrace Saturant). The shear stress-strain curves can be estimated based on Method 1. The Chi-square goodness-of-fit test [46] showed that the shear strength and shear modulus of the adhesive followed Weibull distributions, and the plastic shear strain follows a lognormal distribution. The COV for shear strength, $\tau_{\mathrm{p}}$, shear modulus $G_{\mathrm{a}}$ and plastic shear strain $\gamma_{\mathrm{p}}$ are $4.9 \%, 4.3 \%$ and $19.8 \%$, respectively. The statistical properties of this adhesive were taken to represent the statistics of the five structural adhesive studied here.

\subsubsection{Elastic Modulus of CFRP}

For unidirectional wet lay-up CFRP made of three layers of fiber fabrics, the COV of the modulus in the fiber direction was found to be $9.5 \%$ and follows Weibull distribution [47]. For pultruded CFRP, the COV of the modulus was found to be $0.8 \%$ [39], which is one order of magnitude lower than wet lay-up CFRP so it was treated deterministically in this study.

\subsection{Geometric Property Variables}


Due to different manufacturing processes, the uncertainty of the geometric properties varies greatly. The COV of the thickness of pultruded CFRP laminate is negligible [39] and the geometry of the steel plate is often treated deterministically due to its low variability $[38,40]$. However, the thickness of the adhesive layer and the thickness of CFRP manufactured by wet lay-up techniques exhibit relatively high uncertainty, so they were treated as random variables.

\subsubsection{Adhesive Thickness}

The adhesive thickness is difficult to measure especially for wet lay-up CFRP specimens since the boundary between the fiber fabric and adhesive is not distinct, so an approximate method was used to back calculate the adhesive thickness [31]. For specimens using pultruded CFRP laminate, by measuring the total specimen thickness and subtracting the thickness of adherends, the adhesive thickness can be determined [33]. Based on a group of data measured from CFRP laminate specimens (13 measurements, [33]), the Chi-square goodness-of-fit test showed that lognormal distribution fits the data best, the COV was calculated to be $9.8 \%$, for an average adhesive thickness of $0.372 \mathrm{~mm}$.

\subsubsection{CFRP Thickness}

For wet lay-up CFRP due to the insufficient thickness control during manufacturing, the CFRP thickness was treated as a random variable. For unidirectional wet lay-up CFRP made of three layers of fiber fabrics, the thickness follows a normal distribution and the COV is $4.5 \%$, and the average thickness is $2.74 \mathrm{~mm}[47]$.

\subsection{Resistance Model Uncertainty}

The resistance model uncertainty, $\xi_{R}$, as defined in Eqn. (8), was quantified for the Hart-Smith model using the material input from the literature. In total, 270 specimens that were fabricated using five 
different structural epoxy adhesives were compiled from 12 studies. All of these specimens either failed by debonding in the adhesive layer (cohesive failure) or at the steel-adhesive interface (adhesive failure). Specimens that failed in the adherends (such as CFRP delamination or rupture, or steel yielding) were excluded. While the Hart-Smith model does not account for adhesive failure modes, these are also classified as "debonding" type failures and can often be difficult to distinguish from cohesive failures when a mixed-mode failure occurs. As such, specimens that failed in an adhesive mode were included in the database which also provided an opportunity to investigate the influence of surface preparation on the uncertainty of the bonded joint capacity. The outer adherends (CFRPs) of all of the specimens in the database were thin enough to neglect the peeling stress, as calculated by Eqn. (1). The complied experimental database is given in Table 2.

The model uncertainty depends on the method used to determine the adhesive shear stress-strain response. Al-Mosawe et al. [22] tested 66 steel-CFRP DLS specimens that were produced using the Araldite 420 adhesive and pultruded CFRP laminate with a sand-blasted surface preparation for the steel. This dataset provides the opportunity to evaluate the effect of the adhesive model used on the uncertainty of the resistance model. Figure 4 compares the measured and predicted bond strengths of all of the DLS specimens presented in Al-Mosawe et al. [22] based on the three different adhesive models used for the Araldite 420 adhesive. Inspection of the figure indicates that using the tensile properties to predict the shear response of the adhesive results in a very poor predictive capacity of the model. This is because of the very low estimated shear ductility of the adhesive obtained using this approach. As a result of this low ductility, the calculated critical bond length of the joints is only $41 \mathrm{~mm}$. Thus, essentially all of the tested DLS specimens had bond lengths greater than this value and the model does not accurately represent the effect of the bond length on the joint capacity. This resulted in a very high model bias of 4.11 and COV of $25.0 \%$. In contrast, when the experimentally derived shear stress-strain response is used 
to predict the joint capacity, the model predicts the capacity well with a bias of 1.62 and a COV of $14.4 \%$. Using the adhesive properties obtained through optimization gives similar results with a bias of 1.15 and COV of $14.1 \%$. This indicates that the optimization approach for determining the shear properties yields sufficiently accurate results and will be used for the remaining analysis.

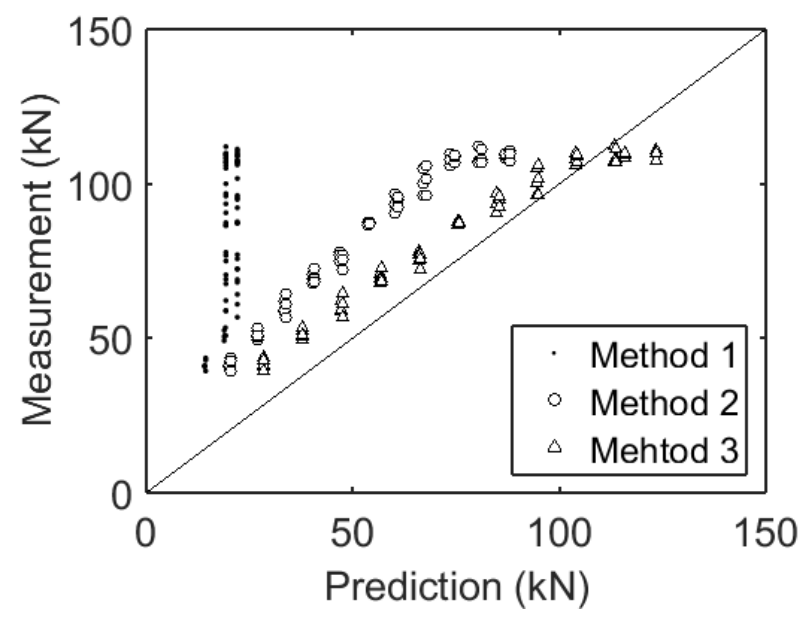

Figure 4 Comparison of the bond strength predicted by different material input for adhesive Araldite 420 using sand-blasting 
Table 2 Database of CFRP-to-steel bonded DLS joints to characterize model uncertainty

\begin{tabular}{|c|c|c|c|c|c|c|c|c|c|c|c|c|c|c|c|}
\hline Ref. & $\begin{array}{c}\text { Specimen } \\
\text { ID }\end{array}$ & Adhesive $^{\mathrm{a}}$ & Surface $^{b}$ & $\begin{array}{l}\text { CFRP } \\
\text { Type }^{\mathrm{c}}\end{array}$ & $\begin{array}{l}\text { Failure } \\
\text { Mode }^{d}\end{array}$ & $\begin{array}{l}E_{\text {CFRP }} \\
(\mathrm{GPa})\end{array}$ & $\begin{array}{c}b_{\mathrm{p}} \\
(\mathrm{mm})\end{array}$ & $\begin{array}{l}t_{\text {CFRP }} \\
(\mathrm{mm})\end{array}$ & $\begin{array}{l}t_{\text {Steel }} \\
(\mathrm{mm})\end{array}$ & $\begin{array}{c}t_{\mathrm{a}} \\
(\mathrm{mm})\end{array}$ & $\begin{array}{c}l \\
(\mathrm{~mm})\end{array}$ & $\begin{array}{c}P_{\mathrm{m}} \\
(\mathrm{kN})\end{array}$ & $\begin{array}{c}P_{\mathrm{p}} \\
(\mathrm{kN})\end{array}$ & $\xi_{R}$ & Number \\
\hline \multirow[t]{3}{*}{ [31] } & $\begin{array}{c}1 \text { st- } \\
\text { NA250,200 }\end{array}$ & A & $\mathrm{AG}$ & WL & SA & 83.9 & 50 & 1.47 & 6 & 0.47 & $\begin{array}{l}200, \\
250\end{array}$ & $\begin{array}{c}71.6 \text { to } \\
109\end{array}$ & $\begin{array}{l}217 \\
217\end{array}$ & $\begin{array}{c}0.357 \text { to } \\
0.500\end{array}$ & \multirow[t]{4}{*}{20} \\
\hline & $\begin{array}{c}\text { 2nd- } \\
\text { NA150,80 }\end{array}$ & $\mathrm{A}$ & $\mathrm{AG}$ & WL & SA & 83.9 & 50 & 1.47 & 6 & 0.47 & $\begin{array}{l}150 \\
80\end{array}$ & $\begin{array}{c}51.4 \text { to } \\
99.1\end{array}$ & $\begin{array}{l}192 \\
217\end{array}$ & $\begin{array}{c}0.237 \text { to } \\
0.513\end{array}$ & \\
\hline & $\begin{array}{c}\text { 4th- } \\
\text { NA200 }\end{array}$ & $\mathrm{A}$ & $\mathrm{AG}$ & WL & SA & 83.9 & 50 & 1.47 & 10 & 0.47 & $\begin{array}{l}200 \\
200\end{array}$ & $\begin{array}{l}105 \\
108\end{array}$ & $\begin{array}{l}210 \\
210\end{array}$ & $\begin{array}{l}0.501 \\
0.515\end{array}$ & \\
\hline [15] & $\begin{array}{c}2 \mathrm{SN} 40, \\
60\end{array}$ & $\mathrm{~A}$ & $\mathrm{AG}$ & WL & SA & 83.9 & 50 & 1.47 & 5 & 0.47 & $\begin{array}{l}40 \\
60\end{array}$ & $\begin{array}{l}66.2 \\
81.4\end{array}$ & $\begin{array}{l}96.6 \\
145\end{array}$ & $\begin{array}{l}0.686 \\
0.562\end{array}$ & \\
\hline \multirow[t]{2}{*}{ [22] } & $\begin{array}{c}\text { S3-30 to } \\
130\end{array}$ & $\mathrm{~A}$ & SB & PL & SA & 159 & 20 & 1.4 & 10 & 0.50 & $\begin{array}{l}30 \text { to } \\
130\end{array}$ & $\begin{array}{c}40.9 \text { to } \\
110\end{array}$ & $\begin{array}{c}28.3 \text { to } \\
116\end{array}$ & $\begin{array}{c}0.937 \text { to } \\
1.45\end{array}$ & \multirow[t]{2}{*}{66} \\
\hline & $\begin{array}{c}\text { NS-30 to } \\
130\end{array}$ & $\mathrm{~A}$ & SB & PL & SA & 203 & 20 & 1.4 & 10 & 0.50 & $\begin{array}{l}30 \text { to } \\
130\end{array}$ & $\begin{array}{c}39.4 \text { to } \\
111\end{array}$ & $\begin{array}{c}28.5 \text { to } \\
123\end{array}$ & $\begin{array}{c}0.871 \text { to } \\
1.53\end{array}$ & \\
\hline [23] & $\begin{array}{c}\text { P-1- } \\
50 \text { to } 150\end{array}$ & $\mathrm{~S}$ & SB & PL & SA & 176 & 51 & 1.22 & 12.4 & $\begin{array}{l}0.50 \text { to } \\
0.55\end{array}$ & $\begin{array}{l}50 \text { to } \\
150\end{array}$ & $\begin{array}{l}70.3 \text { to } \\
78.7\end{array}$ & $\begin{array}{c}66.2 \text { to } \\
70.1\end{array}$ & $\begin{array}{l}1.00 \text { to } \\
1.14\end{array}$ & 13 \\
\hline
\end{tabular}




\begin{tabular}{|c|c|c|c|c|c|c|c|c|c|c|c|c|c|c|c|}
\hline & $\begin{array}{c}\text { P-2- } \\
50 \text { to } 150\end{array}$ & $S$ & SB & PL & SA & 176 & 51 & 2.44 & 12.4 & $\begin{array}{c}0.49 \text { to } \\
0.55\end{array}$ & $\begin{array}{l}50 \text { to } \\
150\end{array}$ & $\begin{array}{c}95.5 \text { to } \\
109\end{array}$ & $\begin{array}{c}93.7 \text { to } \\
104\end{array}$ & $\begin{array}{c}0.984 \text { to } \\
1.50\end{array}$ & \\
\hline [33] & $\begin{array}{l}\text { S30 to } \\
250\end{array}$ & $\mathrm{~S}$ & SB & PL & $\mathrm{C}$ & 479 & 50 & 1.47 & 6 & $\begin{array}{c}0.34 \text { to } \\
0.40\end{array}$ & $\begin{array}{l}30 \text { to } \\
250\end{array}$ & $\begin{array}{c}58.5 \text { to } \\
151\end{array}$ & $\begin{array}{c}55.3 \text { to } \\
113\end{array}$ & $\begin{array}{l}1.06 \text { to } \\
1.55\end{array}$ & \\
\hline \multirow[t]{3}{*}{ [48] } & $\mathrm{J} 1,2$ & $\mathrm{~S}$ & $\overline{\mathrm{AG}}$ & PL & SA & 197 & 60 & 1.4 & 6 & 1.1 & 60 & $\begin{array}{l}118 \\
120\end{array}$ & 148.1 & $\begin{array}{l}0.794 \\
0.813\end{array}$ & \multirow[t]{7}{*}{29} \\
\hline & $\mathrm{J} 3,4$ & $\mathrm{~S}$ & $\overline{A G}$ & PL & SA & 197 & 30 & 1.4 & 10 & 1.1 & 60 & $\begin{array}{l}52.5 \\
55.1\end{array}$ & 69.2 & $\begin{array}{l}0.758 \\
0.796\end{array}$ & \\
\hline & $\mathrm{J} 5,6$ & $\mathrm{~S}$ & $\overline{A G}$ & PL & SA & 197 & 60 & 1.4 & 10 & 1.1 & 60 & $\begin{array}{l}102 \\
111\end{array}$ & 138 & $\begin{array}{l}0.738 \\
0.802\end{array}$ & \\
\hline \multirow[t]{4}{*}{ [20] } & $\begin{array}{l}\mathrm{D} 1,2,3 \\
\mathrm{E} 1,2,3\end{array}$ & $\mathrm{~S}$ & AG & PL & SA & 197 & 30 & 1.4 & 10 & $\begin{array}{c}0.65 \text { to } \\
0.8\end{array}$ & $\begin{array}{c}30 \text { to } \\
60\end{array}$ & $\begin{array}{c}39.7 \text { to } \\
48.8\end{array}$ & $\begin{array}{c}32.7 \text { to } \\
56.7\end{array}$ & $\begin{array}{c}0.798 \text { to } \\
1.33\end{array}$ & \\
\hline & $\mathrm{L} 1,2,3$ & $\mathrm{~S}$ & $\overline{A G}$ & PL & SA & 197 & 60 & 1.4 & 10 & 0.8 & 60 & $\begin{array}{c}91.2 \text { to } \\
96.8\end{array}$ & 113 & $\begin{array}{c}0.805 \text { to } \\
0.853\end{array}$ & \\
\hline & $\mathrm{F} 1,2,3$ & $\mathrm{~S}$ & $\mathrm{AG}$ & PL & SA & 197 & 30 & 1.4 & 10 & 0.9 & 90 & $\begin{array}{c}48.9 \text { to } \\
50.7\end{array}$ & 60.1 & $\begin{array}{c}0.813 \text { to } \\
0.843\end{array}$ & \\
\hline & G1,2 & $\mathrm{S}$ & $\mathrm{AG}$ & PL & SA & 197 & 30 & 1.4 & 10 & 1 & 120 & 51.0 & 63.4 & 0.805 & \\
\hline
\end{tabular}




\begin{tabular}{|c|c|c|c|c|c|c|c|c|c|c|c|c|c|c|c|}
\hline & & & & & & & & & & & & 54.1 & & 0.854 & \\
\hline & $\mathrm{N} 1,2,3,4$ & $\mathrm{~S}$ & $\mathrm{AG}$ & PL & SA & 197 & 30 & 1.4 & 10 & 1 & 120 & $\begin{array}{c}96.3 \text { to } \\
116\end{array}$ & 127 & $\begin{array}{c}0.760 \text { to } \\
0.914\end{array}$ & \\
\hline & $\mathrm{H} 1,2,3$ & $\mathrm{~S}$ & $\mathrm{AG}$ & PL & SA & 197 & 30 & 1.4 & 10 & 1.1 & $\begin{array}{c}120 \text { to } \\
150\end{array}$ & $\begin{array}{c}50.4 \text { to } \\
55.8\end{array}$ & 66.5 & $\begin{array}{c}0.758 \text { to } \\
0.840\end{array}$ & \\
\hline & O1 & $\mathrm{S}$ & $\mathrm{AG}$ & PL & SA & 197 & 60 & 1.4 & 10 & 1.1 & 150 & 109.6 & 133 & 0.825 & \\
\hline [14] & B31,32,33 & TT & $\mathrm{AG}$ & PL & SA & 151 & 51 & 1.5 & 5 & 0.5 & 200 & $\begin{array}{c}72.4 \text { to } \\
88.2\end{array}$ & 118 & $\begin{array}{c}0.612 \text { to } \\
0.746\end{array}$ & 31 \\
\hline \multirow[t]{2}{*}{ [21] } & $\begin{array}{c}\text { DL11,12, } \\
13,14\end{array}$ & TT & $\mathrm{AG}$ & PL & SA & 151 & 25 & 1.5 & 5 & 0.5 & 25 & $\begin{array}{c}14.6 \text { to } \\
17.7\end{array}$ & 7.68 & $\begin{array}{l}1.90 \text { to } \\
2.30\end{array}$ & \\
\hline & $\begin{array}{c}\text { DL21 to } \\
74\end{array}$ & TT & $\mathrm{AG}$ & PL & SA & 151 & 50 & 1.5 & 5 & 0.5 & $\begin{array}{l}50 \text { to } \\
250\end{array}$ & $\begin{array}{c}41.0 \text { to } \\
89.7\end{array}$ & $\begin{array}{c}30.7 \text { to } \\
116\end{array}$ & $\begin{array}{c}0.606 \text { to } \\
1.68\end{array}$ & \\
\hline \multirow[t]{3}{*}{ [14] } & B11,12,13 & TS & $\mathrm{AG}$ & PL & SA & 108 & 51 & 0.51 & 5 & 0.5 & 200 & $\begin{array}{c}26.7 \text { to } \\
31.7\end{array}$ & 33.1 & $\begin{array}{c}0.807 \text { to } \\
0.958\end{array}$ & 38 \\
\hline & B21,22,23 & TS & $\mathrm{AG}$ & $\mathrm{PL}$ & SA & 83 & 51 & 1.0 & 5 & 0.5 & 200 & $\begin{array}{c}29.7 \text { to } \\
41.1\end{array}$ & 41.7 & $\begin{array}{c}0.712 \text { to } \\
0.986\end{array}$ & \\
\hline & DS11,12, & TS & $\mathrm{AG}$ & PL & SA & 83 & 25 & 1.0 & 5 & 0.5 & 13 & 3.5 to & 11.7 & 0.299 to & \\
\hline
\end{tabular}




\begin{tabular}{|c|c|c|c|c|c|c|c|c|c|c|c|c|c|c|c|}
\hline & 13 & & & & & & & & & & & 4.5 & & 0.384 & \\
\hline & DS21 to 74. & $\mathrm{TS}$ & $\mathrm{AG}$ & PL & SA & 83 & 50 & 1.0 & 5 & 0.5 & $\begin{array}{l}50 \text { to } \\
250\end{array}$ & $\begin{array}{c}16.0 \text { to } \\
83.8\end{array}$ & 41.0 & $\begin{array}{c}0.390 \text { to } \\
2.04\end{array}$ & \\
\hline & DS81,82 & TS & $\mathrm{AG}$ & PL & SA & 83 & 94 & 1.0 & 5 & 0.5 & $\begin{array}{l}400 \\
400\end{array}$ & $\begin{array}{l}87.6 \\
97.6\end{array}$ & $\begin{array}{l}77.2 \\
77.2\end{array}$ & $\begin{array}{l}1.14 \\
1.27\end{array}$ & \\
\hline [31] & 3rd-NM200 & MB & $\mathrm{AG}$ & WL & SA & 84.1 & 50 & 1.47 & 6 & 0.47 & 200 & $\begin{array}{c}75.5 \text { to } \\
95.2\end{array}$ & 76.2 & $\begin{array}{c}0.991 \text { to } \\
1.25\end{array}$ & 19 \\
\hline [32] & DS20 to 180 & MB & $\mathrm{AG}$ & WL & SA & 80.8 & 25 & 1.44 & 10 & 0.47 & $\begin{array}{l}20 \text { to } \\
180\end{array}$ & $\begin{array}{l}7.2 \text { to } \\
15.5\end{array}$ & $\begin{array}{c}16.0 \text { to } \\
35.5\end{array}$ & $\begin{array}{c}0.299 \text { to } \\
0.449\end{array}$ & \\
\hline [49] & $\begin{array}{c}\text { DLEPX-1, } \\
2,3,4,5\end{array}$ & MB & $\mathrm{AG}$ & WL & SA & 230 & 37 & 0.165 & 3 & 0.43 & 100 & $\begin{array}{c}32.7 \text { to } \\
44.2\end{array}$ & 28.9 & $\begin{array}{c}1.13 \text { to } \\
1.53\end{array}$ & \\
\hline \multirow[t]{2}{*}{ [24] } & CF-1-MB & MB & SB & WL & SA & 230 & 50 & 0.165 & 5 & 0.50 & $\begin{array}{c}10 \text { to } \\
90\end{array}$ & $\begin{array}{c}19.3 \text { to } \\
45.4\end{array}$ & $\begin{array}{c}15.8 \text { to } \\
41.2\end{array}$ & $\begin{array}{c}0.717 \text { to } \\
1.23\end{array}$ & \multirow[t]{2}{*}{54} \\
\hline & CF-3-MB & MB & SB & WL & $\mathrm{SA}$ & 77.6 & 50 & 1.50 & 5 & 0.50 & $\begin{array}{c}10 \text { to } \\
80\end{array}$ & $\begin{array}{c}24.2 \text { to } \\
81.8\end{array}$ & $\begin{array}{c}16.6 \text { to } \\
77.0\end{array}$ & $\begin{array}{c}0.895 \text { to } \\
1.84\end{array}$ & \\
\hline
\end{tabular}

Notes: a. A=Araldite 420, S=Sikadur 30, TT=Tyfo TC, TS=Tyfo S, MB=Mbrace Saturant; b. AG=Angle-grinding, SB=Sand-blasting; c. WL=Wet lay-up, PL= Pultruded laminate; d. SA=Steel-adhesive interface debonding failure, $\mathrm{C}=$ Cohesive failure 
The modeling uncertainty for each of the groups of DLS specimens is summarized in Table 3 where each group consists of DLS specimens that were fabricated using the same adhesive type, surface preparation technique (sand-blasting or angle-grinding), and CFRP type (wet lay-up or pultruded CFRP).It can be seen that the bias for most cases is close to 1 except using angle-grinding. The COV of the model uncertainty varies greatly among different design scenarios. For example, for the MBrace Saturant specimens using angle-grinding (MB-AG-WL) the COV of the model uncertainty is $62.7 \%$, which indicates large scatter for this configuration. The Chi-square test shows that the model uncertainty can be represented using a lognormal distribution.

Table 3 Model uncertainty for different joint configurations

\begin{tabular}{cccc}
\hline Design Scenario & Number & $\mu\left(\xi_{\mathrm{R}}\right)$ & $\operatorname{COV}\left(\xi_{\mathrm{R}}\right)$ \\
\hline A-SB-PL & 66 & 1.14 & 0.143 \\
A-AG-WL & 20 & 0.446 & 0.220 \\
S-SB-PL & 13 & 1.01 & 0.173 \\
S-AG-PL & 29 & 0.744 & 0.279 \\
TS-AG-PL & 38 & 0.872 & 0.409 \\
TT-AG-PL & 31 & 1.09 & 0.439 \\
MB-SB-WL & 54 & 1.07 & 0.207 \\
MB-AG-WL & 19 & 0.729 & 0.627 \\
\hline
\end{tabular}

Figure 5 compares the predicted and measured tensile failure loads for the five structural adhesives considered in this study and the two different surface preparation techniques. The figure shows that the model consistently overestimates the capacity of joints fabricated with the angle-grinding surface preparation (bias, $\mu\left(\xi_{\mathrm{R}}\right) \leq 1.0$ ) while for sand-blasted surfaces the model predictions are generally more accurate and slightly conservative. This suggests that the angle-grinding surface preparation technique 
generally results in more premature failures which are likely due to the adhesive rather than cohesive nature of the failure mode for these types of specimens.

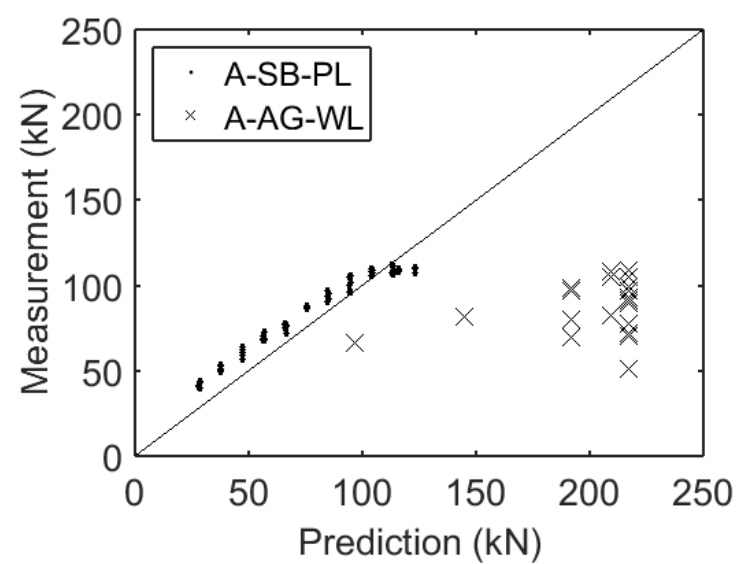

(a) Araldite 420

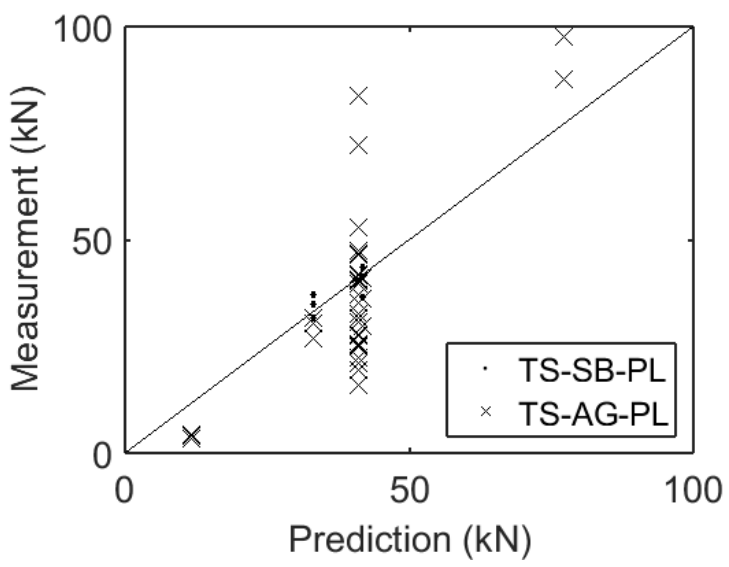

(c) Tyfo S

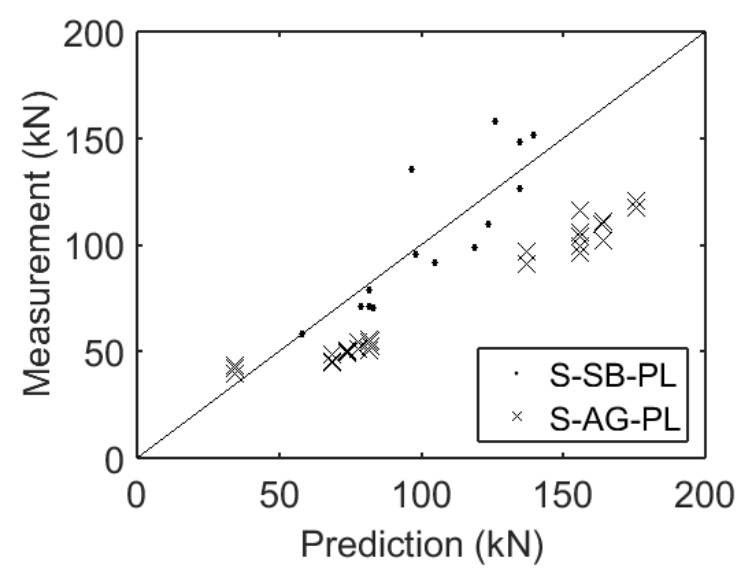

(b) Sikadur 30

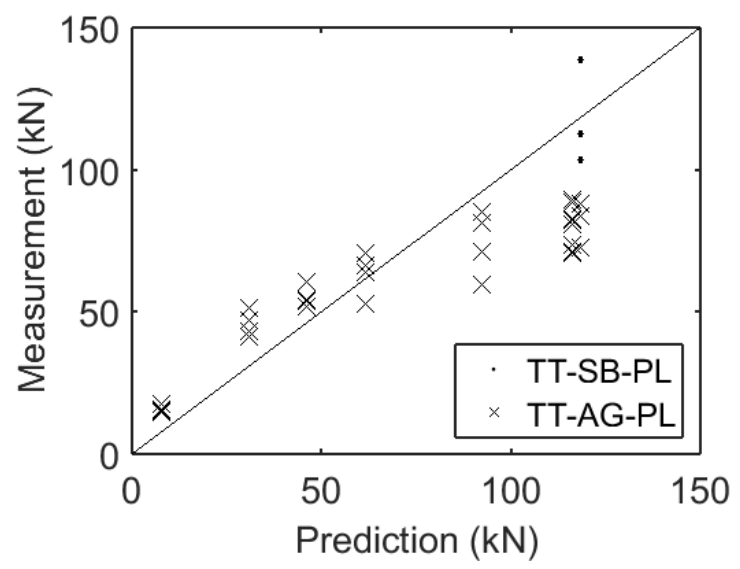

(d) Tyfo TC 


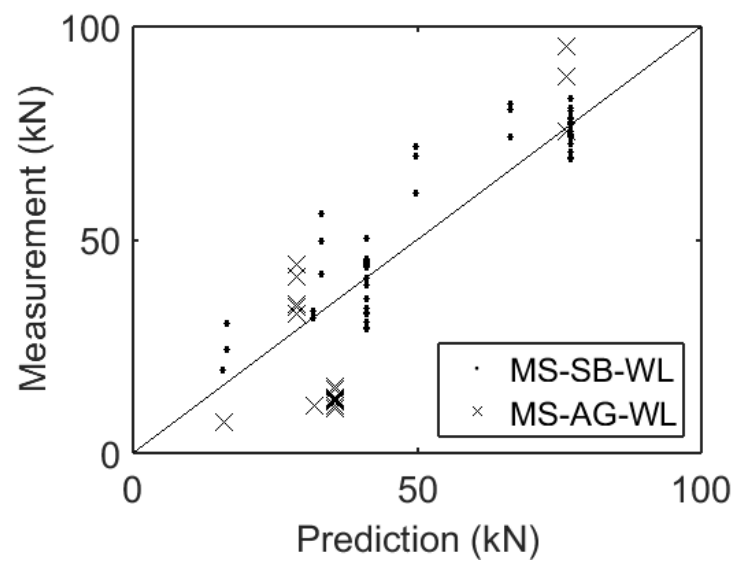

(e) MBrace Saturant

Figure 5 Comparison between measured and predicted bond strength of CFRP-to-steel DLS joint

\subsection{Load Variables}

In the present study, the statistical characteristics of the live load are given in Table 4 according to AASHTO [50] simplified method for bridge design. The rounded load factors, 1.25 and 1.75, are identical to that listed in table 3.4.1-1 of AASHTO LFRD specifications for "Strength I" load combination limit state.

Table 4 Distribution and partial descriptors of analysis factor of load $\zeta_{Q}$

\begin{tabular}{ccccc}
\hline Load & Distribution type & $\lambda_{Q}$ & $\mathrm{COV}_{Q}$ & $\gamma_{Q}$ \\
\hline Dead load & Lognormal & 1.05 & 0.1 & 1.26 (rounded to 1.25) \\
Live load & Lognormal & 0.954 & 0.406 & 1.73 (rounded to 1.75) \\
\hline
\end{tabular}




\subsection{Summary of random variables}

The statistical characteristics of all of the random variables are summarized in Table 5. All of the random variables were assumed to be statistically independent.

Table 5 Statistical characteristics of all the random variables used for reliability analysis

\begin{tabular}{cccc}
\hline Random variable & Bias & COV & Distribution \\
\hline$\tau_{\mathrm{p}}$ & 1.00 & 0.048 & Weibull \\
$G_{\mathrm{a}}$ & 1.00 & 0.024 & Lognormal \\
$\gamma_{\mathrm{p}}$ & 1.00 & 0.198 & Weibull \\
$t_{\mathrm{a}}$ & 1.00 & 0.098 & Lognormal \\
$E_{\mathrm{CFRP}}{ }^{\mathrm{a}}$ & 1.00 & 0.095 & Weibull \\
$t_{\mathrm{CFRP}}{ }^{\mathrm{a}}$ & 1.00 & 0.044 & Normal \\
$\xi_{R}$ & Varies & Lognormal \\
$\zeta_{\mathrm{DL}}$ & 1.05 & Varies & Lognormal \\
$\zeta_{\mathrm{LL}}$ & 0.954 & 0.100 & Lognormal \\
\hline
\end{tabular}

a. for wet lay-up CFRP only, b. Table 3 .

\section{Design Space}

The design space was defined by the availability of an adequately sized database of experimental results. Thus, scenarios that were considered in the design space were selected from an experimental database for combinations of adhesive type, surface preparation technique, adherened types, and joint geometries for which a sufficient number of tests were conducted to provide a reliable dataset. The design space considered in this study is comprised of different design scenarios in Table 3 which include five different adhesive types (Araldite 420, Sikadur 30, Tyfo S, Tyfo TC and Mbrace Saturant), two surface preparation 
techniques (angle-grinding and sand-blasting), and two different types of CFRP/fabrication methods (wet lay-up or pultruded CFRP).

\section{Reliability Analysis}

The methodology for reliability analysis follows a similar procedure to that reported in NCHRP Report No. 368 [37]. The probability of failure $P_{\mathrm{f}}$ is defined as

$$
P_{\mathrm{f}}=\int_{g(\boldsymbol{X})<0} f(\boldsymbol{x}) d \boldsymbol{x}
$$

Where, $f(\boldsymbol{x})$ is the joint probability density function (PDF) of random variables and $g(\boldsymbol{X})<0$ defines the failure domain. The reliability index $\beta$ is calculated as

$$
\beta=-\Phi^{-1}\left(P_{\mathrm{f}}\right)
$$

where $\Phi(\cdot)$ is the cumulative distribution function $(\mathrm{CDF})$ of a normal distribution.

\subsection{FORM analysis}

The first-order reliability method (FORM) was used since it requires less computational effort and the sensitivity analysis can be easily carried out to study the importance of each individual random variable. The integral in Eqn. (21) is obtained by taking the first-order approximation (by Taylor expansion) of the limit state function (Eqn. (19)) in a standard normal space at an optimal point, also called design point. The reliability index is completely defined by the distance $\beta$, from the origin to the design point [51]. In this study, the open source code FERUM [52] was used to perform the FORM analysis. 


\subsection{Monte-Carlo Simulation (MCS)}

In order to validate the FORM results, the limit sate function in Eqn. (19) was solved using MCS. A convergence study was carried out to determine the number of simulations, as shown in Figure 6. In order to achieve good numerical convergence, $N=10,000,000$ was selected as the number of simulation in this study.

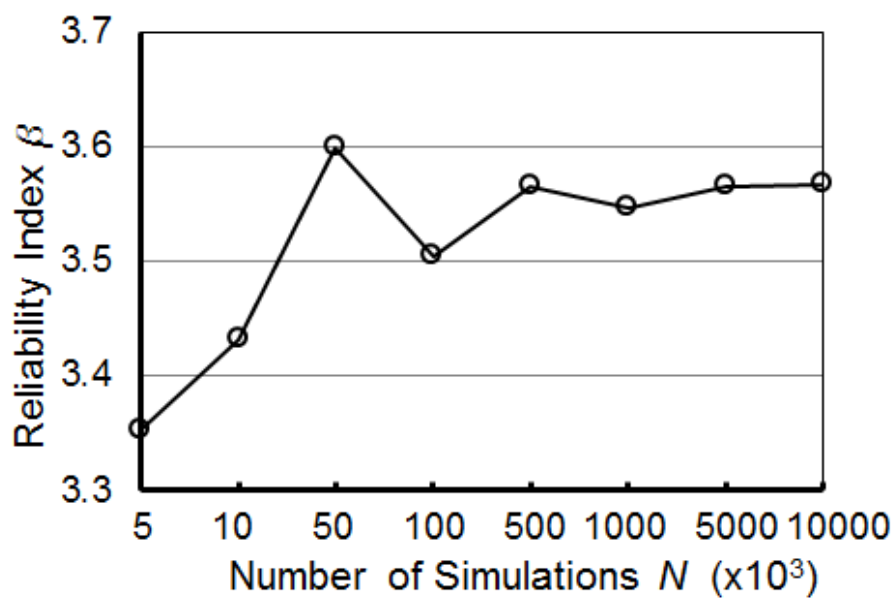

Figure 6 Illustration of numerical convergence study. (A-SB-PL, $\phi=0.60, Q_{\mathrm{LL}} / Q_{\mathrm{DL}}=1$ )

\section{Results and Discussions}

Setting the target reliability index to 3.5 , (which is within the typical range of values adopted by several North America structural steel design standards [50], [53]), the resistance factors for different design cases were calculated by FORM analysis and MCS, as shown in Figure 7. The FORM results agreed well with MCS results in general, and the discrepancy between the two was less than $6 \%$. The difference is due to the first-order approximation of the nonlinear limit state function and the transformation of the random variables. As the non-linearity of the limit state function and/or the non-normality of the random variables increases, the error of FORM analysis increases. 


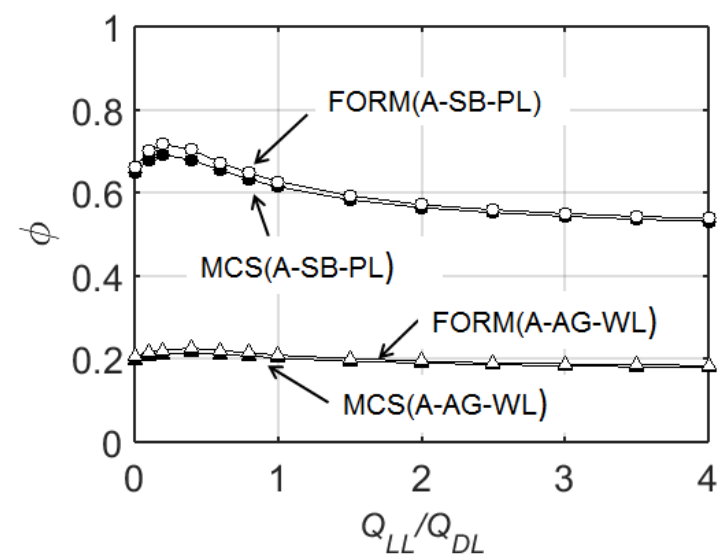

(a) Araldite 420

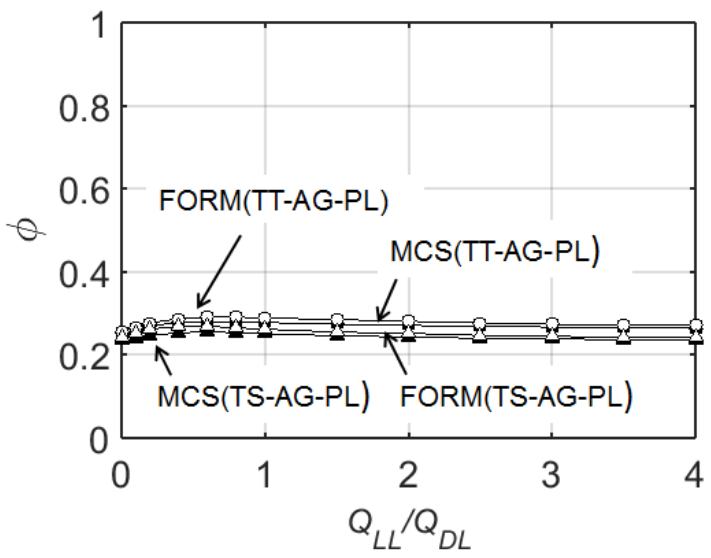

(c) Tyfo TC and Tyfo $\mathrm{S}$

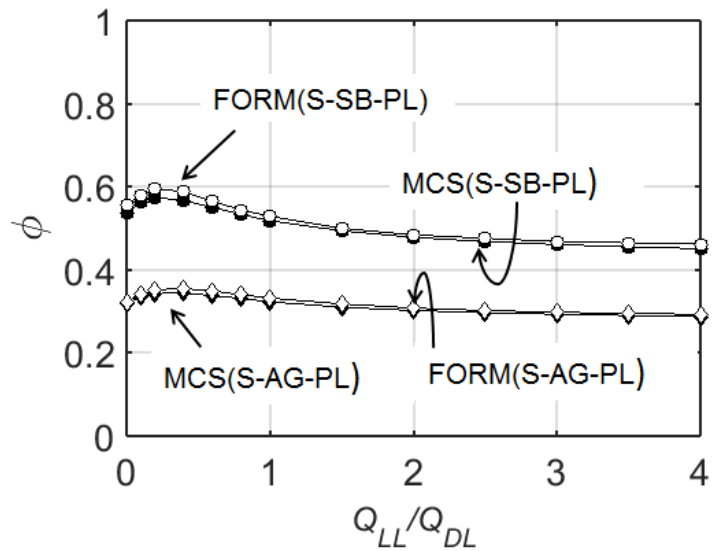

(b) Sikadur 30

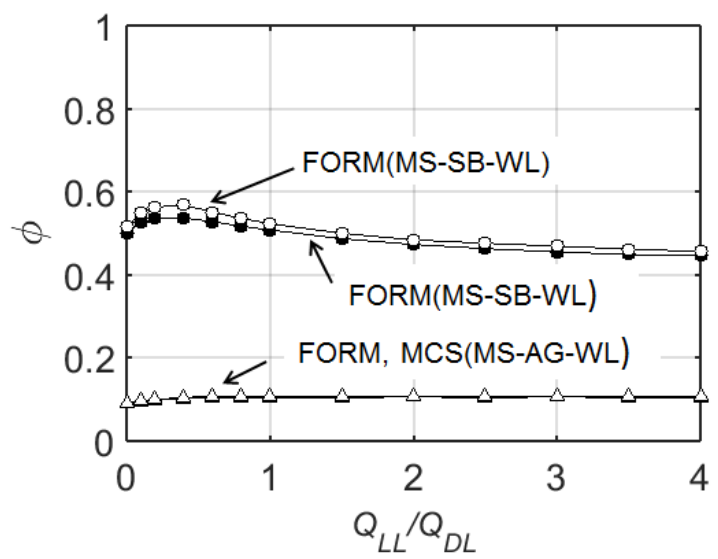

(d) MBrace Saturant

Figure 7 Resistance factors for different design scenarios.

The importance vectors for the random variables and the different scenarios considered in the design space are given in Table 6. This represents the relative contribution of different random variables to the variability of the limit state function. The negative sign represents resistance type of random variable, and the positive sign indicates demand type of random variable. 
Table 6 Importance vector for different design scenarios $\left(Q_{\mathrm{LL}} / Q_{\mathrm{DL}}=1\right)$

\begin{tabular}{cccccccccc}
\hline Design Scenario & $\tau_{\mathrm{p}}$ & $G_{\mathrm{a}}$ & $\gamma_{\mathrm{p}}$ & $t_{\mathrm{a}}$ & $\xi_{\mathrm{R}}$ & $E_{\mathrm{CFRP}}$ & $t_{\mathrm{CFRP}}$ & $\zeta_{\mathrm{DL}}$ & $\zeta_{\mathrm{LL}}$ \\
\hline A-SB-PL & -0.0766 & 0.00140 & -0.288 & 0.000 & -0.427 & N.A. & N.A. & 0.0828 & 0.850 \\
A-AG-WL & -0.0687 & 0.00125 & -0.260 & 0.000 & -0.591 & -0.158 & -0.0642 & 0.0835 & 0.736 \\
S-SB-PL & -0.0776 & 0.00338 & -0.266 & 0.000 & -0.488 & N.A. & N.A. & 0.0831 & 0.824 \\
S-AG-PL & -0.0704 & 0.00306 & -0.244 & 0.000 & -0.634 & N.A. & N.A. & 0.0838 & 0.726 \\
TT-AG-PL & -0.0559 & 0.00551 & -0.172 & 0.000 & -0.851 & N.A. & N.A. & 0.0776 & 0.488 \\
TS-AG-PL & -0.0994 & 0.0333 & -0.0314 & 0.0000 & -0.835 & N.A. & N.A. & 0.0798 & 0.533 \\
MB-SB-WL & -0.0775 & 0.00437 & -0.242 & 0.0000 & -0.568 & -0.161 & -0.0651 & 0.0837 & 0.759 \\
MB-AG-WL & -0.0421 & 0.000327 & -0.139 & 0.0000 & -0.916 & -0.083 & -0.0370 & 0.0676 & 0.356 \\
\hline
\end{tabular}

\subsection{Influence of surface preparation}

As shown in Figure 7, sand-blasting consistently gives higher resistance factors for these three adhesives: Araldite 420, Sikadur 30 and MBrace Saturant. However, the angle-grinding technique gives much lower resistance factors even for the same adhesives, because either the model bias is low or the COV of the model uncertainty is high, as shown in Table 3. This observation reveals that the specimen quality by using angle-grinding is not as consistent as that using sand-blasting. The calculated resistance factors, $\phi$, can be as much as five times higher for sand-blasted specimens than that for specimens prepared by angle-grinding given the same adhesive in both cases. In fact, the largest calculated resistance factor for design scenarios including angle-grinding was 0.35 while the lowest calculated resistance factor for design scenarios including sand-blasting was 0.45 . 


\subsection{Influence of model uncertainty}

As shown in Table 6, among all of the resistance type random variables, the model uncertainty contributes most to the variability of the limit state function. This indicates that the model uncertainty is the most important resistance type of random variable in determining the probability of failure and hence the resistance factor.

\subsection{Influence of adhesive shear strength and ductility}

Adhesive shear strength and ductility are important in determining the adhesive shear toughness. Higher adhesive shear strength is usually preferred to enhance the bond strength. However, higher bond strength cannot always be achieved if, for example, an inferior surface preparation technique is used. Tyfo $\mathrm{S}$ has the highest adhesive strength, but the resistance factors for the TS-AG-PL design scenario is low (0.2 to $0.3)$.

It is particularly notable that the importance vector indicates that the adhesive ductility is more influential than the adhesive strength. Conventionally, more emphasis is put on improving joint performance by increasing adhesive strength rather than by increasing adhesive ductility. The results suggest that more attention on adhesive ductility may be merited. However, the resistance factors for the most ductile adhesive Tyfo TC [14], are relatively low (Figure 7(c)), even compared with the brittle adhesive Sikadur 30 (Figure 7(b)). The adhesive ductility might not be fully engaged if interfacial failure occurs rather than cohesive failure in the adhesive. Therefore, appropriate surface preparation techniques should be adopted to fully engage the ductile adhesives to prevent premature failure. 


\subsection{Influence of adhesive shear modulus}

The shear modulus plays an important role in transferring the load from the steel substrate to CFRP outer adherends. The flexibility of the adhesive layer can greatly influence the magnitude of the peek stresses within the adhesive layer. Table 6 shows that adhesive shear modulus is a demand type of random variable (positive sign). So decrease of the shear modulus can help to increase the bond strength. The importance value for shear modulus is not as high as other material variables. However, this should be balanced with the need for a stiff bond line to provide the necessary degree of composite interaction in strengthening and service load enhancement applications.

\subsection{Influence of adhesive layer thickness}

The traditional rationale is that adhesive layer thickness influences the stress and strain distributions at the joint end, especially for peeling stresses. For the design scenarios considered in the current study, the thin-adherend criterion was satisfied and peeling stresses were negligible. The results show that the adhesive layer thickness plays a negligible role in affecting the resistance factor (Table 6) for joint configurations that are dominated by shear stresses. If peeling stresses are significant, the adhesive layer thickness and modulus may be more influential.

\subsection{Influence of live load to dead load ratio}

The resistance factor varies with the live load to dead load ratio. As the live-to-dead load ratio increases, the resistance factor first increases and then reduces and approaches a constant as the ratio increases. This is because the demand model is a linear combination of dead load and live load. As the live load to dead load ratio increases, the demand model transitions from being dead-load dominated to being live-load dominated, each of which has different statistical characteristics. The variation range of the resistance 
factor is less than 0.2 , for simplicity and conservativeness, the minimum resistance factor is usually recommended for design.

\subsection{Implications of constant resistance factor $\phi=0.45$}

In LFRD design, constant resistance factors are adopted for different structure configurations and the associated failure modes. In order to study the effects of resistance factor on reliability indices, $\phi=0.45$ was selected to calculate the reliability indices. Due to the great impact of surface preparation techniques on bond strength, the design scenarios were grouped by different surface preparation techniques, as shown in Figure 8. It was found that this resistance factor yields reliability indices above or close to 3.5 for all design scenarios if sand-blasting is used, as shown in Figure 8(a). Angle-grinding yielded reliability indices well below the target reliability index of 3.5 as illustrated in Figure 8(b). This supports the conclusion that sand-blasting is more suitable than angle-grinding in steel surface preparation.

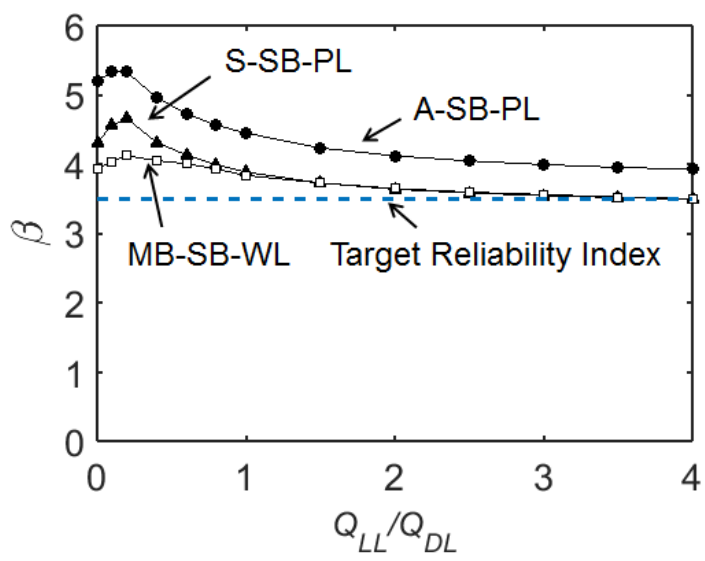

(a) sand-blasting

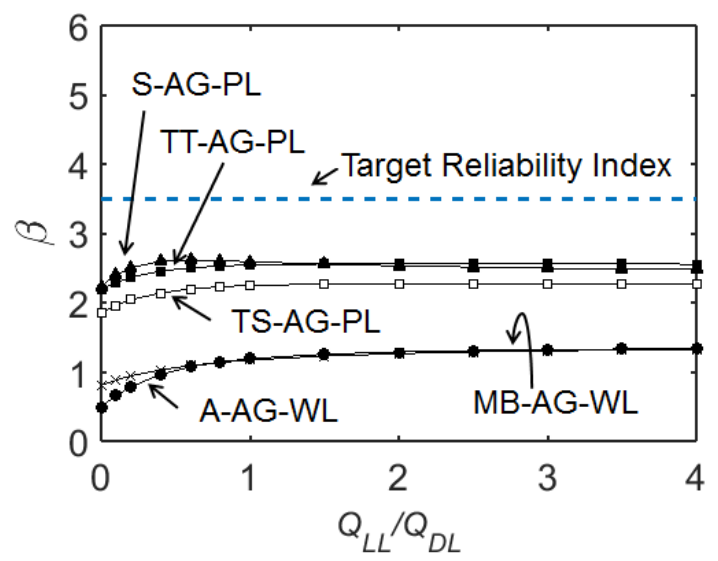

(b) angle-grinding

Figure 8 Reliability indices for different surface preparation techniques. 
The results show that the most important resistance variable in predicting the debonding failure of CFRPto-steel DLS joints is the model uncertainty. The variation of the limit state function can be reduced (hence increasing the resistance factor) if a more accurate analytical model (i.e., the bias closer to unity and reduced COV of the model uncertainty) is adopted to predict the debonding failure. However, this need for accuracy must be balanced with the ease of use of the model for design applications. The resistance factor can also be increased if more accurate information about the mechanical properties of the adhesives and their statistical characteristics is available. Adhesive with high shear toughness but lower shear modulus and pultruded CFRP with higher modulus are preferred to increase joint capacity. Surface preparation is also critical in achieving a reliable bond between CFRP and steel, and sand-blasting is preferable to angle-grinding. Reducing the variability of the adhesive layer thickness plays a negligible role in increasing the resistance factor for DLS joints with thin CFRP adherend, based on the findings of the current study. However, for joints with thicker adherends, in which peeling stresses are more significant, the effect of adhesive thickness may be more significant.

\section{Summary and Conclusions}

This paper studied the reliability of adhesively bonded CFRP-to-steel DLS joints with thin outer adherends, for different design scenarios. The major findings of this paper are:

(1) The model uncertainty is highly influenced by the design scenario being considered. The modeling uncertainty is the most important demand type random variable affecting the reliability index. This suggests that developing accurate and robust bond models can have significant impact on the reliability of bonded joints in design applications and could dramatically influence the resistance factors that are used for bond. 
(2) The analysis results indicate that the adhesive plastic shear strain capacity is the most influential material property when considering bond strength and reliability. The importance vector indicates that adhesive plastic shear strain (ductility) has a greater influence on the bond strength and reliability than the adhesive strength. However, large adhesive ductility does not necessarily lead to high resistance factors due to the effect of surface preparation and premature adhesive failure on the bond behavior. Adhesive shear modulus is a demand-type random variable since increasing shear stiffness increases the magnitude of stress concentrations near the joint ends.

(3) Using adhesive properties from uniaxial tensile tests as the material input might greatly underestimate the adhesive shear ductility and consequently the ultimate capacity of bonded joints. Mechanical properties of adhesive (shear strength and plastic shear strain capacity) obtained directly from shear tests can provide a better representation of the true behavior of the adhesive layer of DLS joints. In the absence of standard tests to determine the adhesive shear stress-strain response, an optimization approach was presented to predict the adhesive shear properties. The optimization approach gives acceptable estimates of the adhesive response and the modeling uncertainty when compared to using the actual adhesive shear response. However, this approach requires the presence of a sufficiently large database of test results using the selected adhesive, surface preparation technique, and CFRP type to be feasible and is too computational involved for most design applications.

(4) Surface preparation using sand-blasting consistently gives higher resistance factors than anglegrinding, suggesting less uncertainty while angle-grinding led to inconsistent reliability. For Araldite 420, MBrace Saturant and Sikadur 30 using sand-blasting surface preparation techniques, a constant resistance factor of 0.45 leads to reliability indices consistently near or greater than the target reliability of 3.5 . 
(5) In order to better design and analyze FRP-steel bond, the stress-strain relationship of the adhesive under shear loading (possibly combined with peeling) is needed. This will help to bridge the gap between mechanical properties of adhesive and the structural performance of the bonded joints.

\section{Acknowledgements}

This work was supported by the National Science Foundation [CMMI Award \#1334838] and the Department of Civil and Environmental Engineering at the University of Houston. 


\section{References}

[1] R. Sen, L. Liby, and G. Mullins, Strengthening steel bridge sections using CFRP laminates, Compos. Part B. 32(2001) 302-322.

[2] M. Tavakkolizadeh and H. Saadatmanesh, Repair of damaged steel-concrete composite girders using carbon fiber-reinforced polymer sheets, J. Compos. Constr. 7(4) (2003) 311-322.

[3] M. Dawood, S. Rizkalla, and E. Sumner, Fatigue and overloading behavior of steel-concrete composite flexural members strengthened with high modulus CFRP materials, J. Compos. Constr. 11(6) (2007) 659-669.

[4] S. Rizkalla, M. Dawood, and D. Schnerch, Development of carbon fiber reinforced polymer system for strengthening steel structures, Compos. Part A. 39(2008) 388-397.

[5] D, Fernando, T. Yu, J.G. Teng, and X.L. Zhao, CFRP strengthening of rectangular steel tubes subjected to end bearing loads: Effect of adhesive properties and finite element modelling, Thin. Wall. Struct. 47(10) (2009) 1020-1028.

[6] J.G. Teng, T. Yu, and D. Fernando, Strengthening of steel structures with fiber-reinforced polymer composites, J. Constr. Steel. Res. 78(2012) 131-143.

[7] P. Colombi and F. Giulia, Fatigue behaviour of tensile steel/CFRP joints, Compos. Struct. 94(8) (2012) 2407-2417.

[8] X.L. Zhao, FRP-strengthened metallic structures, CRC Press, Boca Raton, FL, 2014.

[9] M.U. Sahin and M. Dawood, Experimental investigation of bond between high-modulus CFRP and steel at moderately elevated temperatures. J. Compos. Constr. 20(6) (2016) 04016049.

[10] X. Liu, P.F. Silva, and A. Nanni, Rehabilitation of steel bridge members with FRP composite materials. In: Composites in Construction, Proceedings of the International Conference Composite in Construction (CCC 2001), Porto, Portugal, 10-12 October 2001. pp. 613-618. 
[11] D. Schnerch, M. Dawood, S. Rizkalla, E. Sumner, K. Stanford, Bond behavior of CFRP strengthened steel structures, Adv. Struct. Eng. 9(6) (2006) 805-817.

[12] K. Harries and M. Dawood, Behavior and performance of fiber-reinforced polymer-to-steel bond, J. Transp. Res. Brd. 2313 (2012) 181-188.

[13] H. Kazem, L.Guaderrama, H. Selim, S. Rizkalla, A. Kobayashi, Strengthening of steel plates subjected to uniaxial compression using small-diameter CFRP strands, Constr. Build. Mater. 111(2016) 223-236.

[14] Y. Yu, Static and cyclic behavior of steel beams retrofitted with fiber reinforced polymer laminates, PhD thesis, Nanyang Technological University, Singapore, 2008.

[15] H.B. Liu, X.L. Zhao, and R. Al-Mahaidi, Effect of fatigue loading on bond strength between CFRP sheets and steel plates, Int. J. Struct. Stab. Dy. 10(2010) 1-20.

[16] R. Rameshni, S. Arcovio, M. Green, and C. MacDougall, Experimental and numerical study of adhesively bonded glass fibre-reinforced polymer-to-steel double-shear lap splices, Can. J. Civil. Eng. 40(2013) 1140-1149.

[17] D. Fernando, J.G. Teng, T. Yu, and X.L. Zhao, Preparation and characterization of steel surfaces for adhesive bonding, J. Compos. Constr. 17(6)(2013) 04013012.

[18] S. Fawzia, X.L. Zhao, R. Al-Mahaidi, and S. Rizkalla, Double strap joint tests to determine the bond characteristics between CFRP and steel plates, Adv. Steel. Struct. 2(2005) 1583-1588.

[19] L.C. Hollaway, L. Zhang, N.K. Photiou, J.G. Teng, and S.S. Zhang, Advances in adhesive joining of carbon fiber polymer composites to steel members for repair and rehabilitation of bridge structures, Adv. Struct. Eng. 9(2006) 791-803.

[20] M. Bocciarelli, P. Colombi, G. Fava, and C. Poggi, Prediction of debonding strength of tensile steel/CFRP joints using fracture mechanics and stress based criteria, Eng. Frac. Mech. 76 (2009) 299-213. 
[21] S.P. Chiew, Y. Yu, and C.K. Lee, Bond failure of steel beams strengthened with FRP laminates Part 1: Model development, Compos. Part B. 42(2011) 1114-1121.

[22] A. Al-Mosawe, R. Al-Mahaidi, X.L. Zhao, Effect of CFRP properties on the bond characteristics between steel and CFRP laminate under quasi-static loading, Constr. Build. Mater. 98(2015) 489501.

[23] A. Lam, J.J.R. Cheng, M.C.H. Yam, and G.D. Kennedy, Repair of steel structures by bonded carbon fiber reinforced polymer patching: experimental and numerical study of carbon fiber reinforced polymer, Can. J. Civil. Eng. 34(2007) 1542-1553.

[24] H. Al-Zubaidy, R. Al-Mahaidi, and X.L. Zhao, Experimental investigation of bond characteristics between CFRP fabrics and steel plate joints under impact tensile loads, Compos. Struct. 94(2012) $510-518$.

[25] CIRIA C595, Strengthening metallic structures using externally bonded fiber-reinforced polymers, CIRIA, London, 2004.

[26] CNR-DT 203, Guide for the design and construction of externally bonded FRP systems for strengthening existing structures, Italian Advisory Committee on Technical Recommendations for Construction, Rome, 2005.

[27] L.J. Hart-Smith, Adhesive-bonded double-lap joints, Technical Report NASA CR-112235, McDonnell Douglas Corporation, Long Beach, California, 1973.

[28] A.M. Albat and D.P. Romilly, A direct linear-elastic analysis of double symmetric bonded joints and reinforcements, Compos. Sci. Technol. 59(1999) 1127-1137.

[29] J.J. Radice and J.R. Vinson, On the analysis of adhesively bonded structures: A high order semielastic adhesive layer model, Compos. Sci. Technol. 68(2008) 376-386.

[30] H. Osnes, D. McGeorge, J.R. Weitzenböck, and G.O. Guthu, Predicting failure of bonded patches using a fracture mechanics approach, Int. J. Adhes. Adhes. 37(2012) 102-111. 
[31] S. Fawzia, X.L. Zhao, and R. Al-Mahaidi, Bond slip models for double strap joints strengthened by CFRP, Compos. Struct. 92 (2010) 2137-2145.

[32] S. Fawzia, Evaluation of shear stress and slip relationship of composite lap joints, Compos. Struct. 100 (2013) 548-553.

[33] C. Wu, X.L. Zhao, W.H. Duan, and R. Al-Mahaidi, Bond characteristics between ultra-high modulus CFRP laminates and steel, Thin. Wall. Struct. 51 (2012) 147-157.

[34] X.L. Zhao and L. Zhang, State-of-the-art review on FRP strengthened steel structures, Eng. Struct. 29(8) (2007) 1808-1823.

[35] T. Allen, A.S. Nowak, R.J. Bathurst, Calibration to determine load and resistance factors for geotechnical and structural design, Transportation Research Circular E-C079, Transportation Research Board, Washington DC, USA, 2005.

[36] D.V. Val, Reliability of fiber-reinforced polymer-confined reinforced concrete columns, J. Struct. Eng. 129 (2003) 1122-1130.

[37] A.S. Nowak, Calibration of LRFD bridge design code, NCHRP Report 368, National Cooperative Highway Research Program, 1999.

[38] N. Wang, B.R. Ellingwood, and A. Zureick, Reliability-based Evaluation of flexural members strengthened with externally bonded fiber-reinforced polymer composites, J. Struct. Eng. 136(9) (2010) 1151-1160.

[39] A. Zureick, L. Kahn, and Y. Kim, Strengthening of reinforced concrete bridge deck slabs with shopmanufactured carbon composite plates, Report No. 02-3, Georgia Institute of Technology, Atlanta, 2002.

[40] N. Plevris, T. Triantafillou, and D. Veneziano, Reliability of RC members strengthened with CFRP laminates, J. Struct. Eng. 121(7) (1995) 1037-1044. 
[41] ASTM D638-14, Standard test method for tensile properties of plastics, ASTM International, West Conshohocken, PA, 2014.

[42] N. Arnaud, R. Créac'Hcadec, and J.Y. Cognard, A tension/compression-torsion test suited to analyze the mechanical behavior of adhesives under non-proportional loadings, Int. J. Adhes. Adhes. 53 (2014) 3-14.

[43] S. Fawzia, Bond characteristics between steel and carbon fiber reinforced polymer (CFRP) composites, PhD Thesis, Monash University, Vicotoria, Australia, 2008.

[44] A. Argon, The Physics of Deformation and Fracture of Polymers, Cambridge University Press, Cambridge, 2013.

[45] G. Bresson, J. Jumel, M.E.R. Shanahan, and P. Serin, Statistical aspects of the mechanical behavior a paste adhesive, Int. J. Adhes. Adhes. 40 (2013) 70-79.

[46] A.H.S. Ang, and W.H. Tang, Probability concepts in engineering: emphasis on applications to civil and environmental Engineering, John Wiley \& Sons, Inc., 2006.

[47] R. Atadero, L. Lee, and V.M. Karbhari, Consideration of material variability in reliability analysis of FRP strengthened bridge decks, Compos. Struct. 70 (2005) 430-443.

[48] M. Bocciarelli, P. Colombi, G. Fava, and C. Poggi, Interaction of interface delamination and plasticity in tensile steel members reinforced by CFRP plates, Int. J. Fracture. 146 (2007) 79-92.

[49] Y.J. Kim, J. LaBere, and I. Yoshitake, Hybrid epoxy-silyl modified polymer adhesives for CFRP sheets bonded to a steel substrate, Compos. Part B. 51 (2013) 233-245.

[50] AASHTO, LFRD bridge design specifications, American Association of State Highway and Transportation Officials, Whshington, DC, 2012.

[51] E. Nikolaidis, D.M. Ghiocel, and S. Singhal, Engineering design reliability handbook, CRC Press Boca Raton, FL, 2005

[52] T. Haukaas and A. Der Kiureghian, http://www.ce.berkeley.edu/projects/ferum/index.html. 
[53] AISC (2011), Steel construction manual, 14th ed., American Institute of Steel Construction (AISC), Chicago, U.S.A. 